THE Letters to the Editor section is subdivided into four categories entitled Communications, Notes, Comments, and Errata. The textual material of each Letter is limited to 950 words minus the following: (a) 200 words for each averagesized figure; $(b) 50$ words for each displayed equation; (c) 7 words for each line of table including headings and horizontal rulings. Proof will be sent to authors. See the issue of I July 1973 for a fuller description of Letters to the Editor.

\title{
Notes
}

THE JOURNAL OF CHEMICAL PHYSICS

VOLUME $59, \quad$ NUMBER 9

1 NOVEMBER 1973

\section{Calculated intermolecular interactions in secondary chlorides}

\author{
W. H. Moore and S. Krimm \\ Harrison M. Randall Laboratory of Physics, University of Michigan, Ann Arbor, Michigan 48104
}

(Received 24 April 1973)

In the far infrared spectra of 2-chloropropane, 2-chlorobutane, 3-chlorohexane, and meso-2, 4-dichloropentane, Warrier and Krimm ${ }^{1}$ observed a band at approximately $67 \mathrm{~cm}^{-1}$ which persisted at liquid nitrogen temperatures, disappeared in the spectra of the vapors studied (2-chlorobutane and 2-chloropropane), and also disappeared in the spectrum of 2-chlorobutane in paraffin oil. Moreover, a similar band near $64 \mathrm{~cm}^{-1}$ was observed by them ${ }^{2}$ in the spectrum of poly(vinyl chloride) (PVC) and its deuterated analogs. This absorption, which increased in frequency at liquid nitrogen temperatures, was found to be uniquely associated with the crystalline phase of PVC polymers. Warrier and Krimm suggested ${ }^{1}$ that the evidence supported the assignment of this absorption band near $67 \mathrm{~cm}^{-1}$ in secondary chlorides to a specific weak intermolecular interaction. It was thought that this interaction, which was as sumed to involve specific atoms, might correspond to a $\mathrm{C}-\mathrm{Cl} \cdots \mathrm{H}-\mathrm{C}(\mathrm{Cl})$ type of hydrogen bond. ${ }^{1}$

Recently, we have developed a complete general valence force field for secondary chlorides and related polymers ${ }^{3}$ which includes force constants for a $\mathrm{C}-\mathrm{Cl} \cdots \mathrm{H}-\mathrm{C}(\mathrm{Cl})$ intermolecular interaction. In order to do a normal coordinate calculation which included such an intermolecular bond, some assumption had to be made about the relative orientation of the bonded molecules. For the calculations whose results are reported here, it was postulated that the 2-chloropropane or 2-chlorobutane molecules assumed the same relative orientation as the two molecules in a unit cell of

TABLE I. Observed and calculated intermolecular vibrations in secondary chlorides.

\begin{tabular}{llcll}
\hline \multicolumn{1}{c}{ Molecule } & $\begin{array}{c}\text { Frequency } \\
\text { Room } \\
\text { temp. }\end{array}$ & $\begin{array}{c}\text { Liquid } \\
\mathrm{N}_{2} \text { temp. }\end{array}$ & $\begin{array}{c}\text { Frequency } \\
\text { (Calc) }\end{array}$ & \multicolumn{1}{c}{ PED $^{\mathrm{b}}$} \\
\hline 2-chloropropane & & 69.5 & 70.4 & $\mathrm{XP}(91)$ \\
2-chlorobutane & 67.0 & 67.5 & 65.0 & $\mathrm{XP}(78), \tau(11)$ \\
$\left(\mathrm{CH}_{2} \mathrm{CHCl}\right)_{n}$ & 64.1 & 67.1 & 64.1 & $\mathrm{XP}(13), \alpha_{i p}^{\mathrm{H}}(22), \alpha_{i p}^{\mathrm{Cl}}(29), \tau(32)$ \\
$\left(\mathrm{CD}_{2} \mathrm{CHCl}\right)_{n}$ & 64.0 & 67.1 & 63.8 & $\mathrm{XP}(13), \alpha_{i p}^{\mathrm{H}}(22), \alpha_{i p}^{\mathrm{C} 1}(29), \tau(32)$ \\
$\left(\mathrm{CH}_{2} \mathrm{CDCl}\right)_{n}$ & 63.1 & 65.8 & 63.3 & $\mathrm{XP}(13), \alpha_{i p}^{\mathrm{H}}(22), \alpha_{i p}^{\mathrm{C} 1}(29), \tau(32)$ \\
$\left(\mathrm{CD}_{2} \mathrm{CDCl}\right)_{n}$ & 61.5 & 64.3 & 62.9 & $\mathrm{XP}(13), \alpha_{i p}^{\mathrm{H}}(22), \alpha_{i p}^{\mathrm{C1}}(29), \tau(32)$ \\
\hline \hline
\end{tabular}

${ }^{\mathrm{a}}$ For small molecules, Ref. 1; for polymers, Ref. 2.

${ }^{\mathrm{b}} \mathrm{PED}$ is the potential energy distribution; $\mathrm{XP}, \mathrm{Cl} \cdots \mathrm{H}$ stretch; $\mathrm{T}$, torsion; $\alpha_{i p}^{\mathrm{C} 1}, \mathrm{C}-\mathrm{Cl} \cdots \mathrm{H}$ in plane bend; $\alpha_{i \mathfrak{H}}^{\mathrm{H}}, \mathrm{Cl} \cdots \mathrm{H}-\mathrm{C}$ in plane bend. Contributions $<10 \%$ not included. 
crystalline PVC. ${ }^{4,5}$ Normal coordinate analyses were done on a two-molecule model of 2-chloropropane and 2-chlorobutane with this relative orientation, and with intermolecular stretching and bending force constants added to the intramolecular force field. ${ }^{3} \mathrm{Cl} \cdots \mathrm{H}$ intermolecular vibrations were calculated at 70.4 and $65.0 \mathrm{~cm}^{-1} \mathrm{re-}$ spectively (see Table I). Calculations were also done for other configurations obtained by the rotation of one of the 2-chloropropane molecules with respect to the other around the $\mathrm{Cl} \cdots \mathrm{H}$ bond. For these calculations the results were essentially unchanged.

After the refinement of the general valence force field for secondary chlorides, normal coordinate calculations were done for crystalline PVC and its deuterated derivatives. These calculations support the conclusion reached by Warrier and Krimm ${ }^{2}$ that the $\sim 64 \mathrm{~cm}^{-1}$ band is assignable to an inter molecular vibration (see Table I). (The observed far infrared band at $89 \mathrm{~cm}^{-1}$ is due to an internal torsion.) In the case of the polymer, however, this mode is less purely intermolecular and in fact includes some contribution from internal chain torsion.
Although the intermolecular force field is of necessity somewhat crude at this stage, we see that it satisfactorily reproduces the major observations: the higher frequencies in the small molecules as compared to the polymers, and the trend in the frequencies of the deuterated polymers. (The detailed shifts in the latter will certainly be influenced by possible small changes in crystal structure, about which nothing is presently known.) It had been suggested that the intermolecular interaction might be similar to a hydrogen bond. ${ }^{1}$ The results of an accurate crystal structure analysis ${ }^{5}$ make this unlikely. A dipole-dipole interaction is perhaps a more likely mechanism. ${ }^{6}$

This research was supported by the National Science Foundation under Grant No. GP-27717.

${ }^{1}$ A. V. R. Warrier and S. Krimm, J. Chem. Phys. 52, 4316 (1970).

${ }^{2}$ A. V. R. Warrier and S. Krimm, Macromolecules 3, 709 (1970).

${ }^{3}$ W. H. Moore and S. Krimm, Spectrochim. Acta (to be published).

${ }^{4}$ G. Natta and P. Corradini, J. Polym. Sci. 20, 251 (1956).

${ }^{5}$ C. E. Wilkes, V. L. Folt, and S. Krimm, Macromolecules 6, 235 (1973).

${ }^{6}$ R. J. Jacobsen and J. W. Brasch, J. Am. Chem. Soc. 86, 3571 (1964). 